\title{
Produção científica na enfermagem contribuindo com a inovação e translação do conhecimento
}

\author{
Maria da Graça Oliveira Crossettia ${ }^{a}$ \\ Carolina Giordani da Silva ${ }^{b}$ (id
}

\begin{abstract}
Como citar este artigo: Crossetti MGO, Silva CG. Produção científica na enfermagem contribuindo com a inovação e translação do conhecimento [Editorial]. Rev Gaúcha Enferm. 2019;40:e20190245. doi: https://doi. org/10.1590/1983-1447.2019.20190245
\end{abstract}

A RGE, cumprindo com sua missão e identificada com o movimento de transição e translação do conhecimento, coloca a disposição da comunidade científica o volume 40 cujos artigos resultantes de estudos e pesquisas com diversos enfoques e temáticas convergem para o desenvolvimento da enfermagem como filosofia e ciência.

À análise das produções que compõem este volume, constata-se a prevalência de estudos de natureza qualitativa, na prática clínica. Dados que vêm ao encontro da crescente preocupação dos pesquisadores com os fenômenos inerentes as condições existenciais dos sujeitos protagonistas do processo de cuidar na enfermagem, ou seja, o ser humano. É a busca pelo desvelar de evidências que caracterizam a singularidade do indivíduo expressa por condutas, sentimentos e ou emoções que matizam a ética e estética do cuidado.

A estas evidências, agregam-se aquelas cujo foco dos estudos nas abordagens quantitativas e de revisões de literatura do tipo integrativa e de escopo, sustenta a tomada de decisão clínica que orienta o cuidado aos pacientes, uma vez que são publicações com rigor científico pautado em metodologias bem delineadas e conduzidas por seus autores. Estas condições configuram tecnologias de cuidado inovadoras, por terem sido oriundas de questionamentos teorizados e investigados da e para a prática clínica.

Dentre estas produções, prevalecem estudos com adultos e idosos no contexto de doenças crônicas não transmissíveis e as infectocontagiosas voltadas para o cuidado de enfermagem, e estudos com foco na atenção a mulher, visando a educação em saúde para gestantes de alto risco. Destaca-se o estudo com referencial teórico metodológico da Teoria Fundamentada em Dados (TFD) na atenção primária a gestante.

Este volume contempla, ainda, estudos voltados para assistência pediátrica, buscando compreender a perspectiva desta população acerca da sua condição de saúde, bem como a rede de apoio a família desses pacientes, reforçando a importância de pesquisas de natureza qualitativa, que possibilitam conhecer as especificidades do indivíduo, contribuindo para um cuidado humanizado e integral.

Em atenção ao avanço tecnológico que vem influenciando o processo pedagógico nos seus diferentes níveis, nesta edição se apresenta um artigo que desenvolveu uma tecnologia educacional para apoiar o ensino da Sistematização da Assistência de Enfermagem (SAE) para discentes e/ou enfermeiros. Estudo que expressa o compromisso dos pesquisadores na busca de níveis de excelência na prática clínica, uma vez que esta metodologia de trabalho é privativa do enfermeiro, orienta o processo de julgamento clínico e tomada de decisão frente aos problemas de saúde da população em diferentes

\footnotetext{
a Universidade Federal do Rio Grande do Sul (UFRGS), Escola de Enfermagem, Departamento de Enfermagem Médico Cirúrgica. Porto Alegre, Rio Grande do Sul, Brasil.

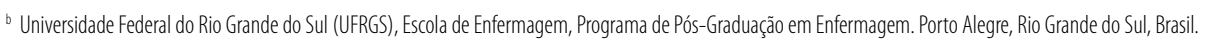


contextos. Corroborando na busca pela acurácia dos processos assistenciais, o volume também apresenta um estudo de adaptação transcultural para cultura brasileira de um instrumento que avalia competências dos enfermeiros hospitalares.

Os resultados oriundos dos estudos apresentados neste volume orientam o cuidado seguro. O número expressivo de estudos voltados para prática assistencial confirma a necessidade permanente de atualização e translação do conhecimento para promoção da saúde, consolidando uma assistência com maior efetividade, beneficiando não só a comunidade, mas também o sistema de saúde como um todo. A produção científica, ora apresentada, reflete a preocupação com o desenvolvimento da enfermagem enquanto disciplina social e humanista. 